\title{
Results of Surgical Treatment of Leg Shaft Mal-Union in Adults at CHU-Brazzaville. A Five Case Retrospective Observation
}

\author{
Marius Monka*, Terence Olivier Ohoya Etsaka, Albert Ngatsé-Oko, Armand Moyikoua \\ Department of Trauma-Orthopedics, CHU-Brazzaville Teaching Hospital, Brazzaville, Congo \\ Email: ^mar_monka@yahoo.fr
}

How to cite this paper: Monka, M., Etsaka, T.O.O., Ngatsé-Oko, A. and Moyikoua, A. (2019) Results of Surgical Treatment of Leg Shaft Mal-Union in Adults at CHU-Brazzaville. A Five Case Retrospective Observation. Open Journal of Orthopedics, 9, 191-196.

https://doi.org/10.4236/ojo.2019.99020

Received: July 10, 2019

Accepted: August 16, 2019

Published: August 19, 2019

Copyright $\odot 2019$ by author(s) and Scientific Research Publishing Inc. This work is licensed under the Creative Commons Attribution International License (CC BY 4.0).

http://creativecommons.org/licenses/by/4.0/

cc) (i) Open Access

\begin{abstract}
Objective: To assess the anatomical and functional results after surgical management of leg shaft mal-union in African environment. Methodology: This was a retrospective study of patients operated for leg mal-union at Brazzaville University Hospital between January 2014 and December 2018. The studied parameters were epidemiological and therapeutic. The anatomical evaluation was based on the quality of the leg's relaxation and bone healing, which was indicated on standard X-rays. The functional evaluation was based on Thorensen's criteria. Results: Five patients were selected for this study. There were 3 men and 2 women with an average age of 39 years with extremes of 27 and 59 years. Three patients were treated with locked intramedullary nail and 2 patients with screwed plate. At an average follow-up of 9 months, bone consolidation was achieved in all our patients. The average consolidation time was 4 months (range 3 to 7 months). We noted 1 case of residual mal-union in valgus $\left(5^{\circ}\right)$ on screwed plate and 1 case of valgus angulation $\left(5^{\circ}\right)$ on locked intramedullary nail. Walking was considered normal in 3 patients. The wearing of a $2 \mathrm{~cm}$ heel was indicated in 2 patients. According to Thorensen's criteria, the overall results were considered good in 3 patients and average in 2 patients. Conclusion: Leg shaft mal-union are likely to cause serious functional issues. Their treatment is strictly surgical and osteotomy is the only management option to restore the anatomy of the deformed limb.
\end{abstract}

\section{Keywords}

Leg Shaft Mal-Union, Leg, Osteotomy

\section{Introduction}

Leg shaft mal-union are one of the late complications of limb fractures [1]. They 
usually occur as the result of poorly conducted initial treatment, where bone fragments have united or consolidated in a non-anatomical position [2]. The measures used to evaluate mal-union are $10^{\circ}$ for varus, flessum, recurvatum and internal rotation, $15^{\circ}$ for valgus and external rotation, $2 \mathrm{~cm}$ for shortening [3]. In North American literature, they are $5^{\circ}$ for angulation, $10^{\circ}$ for rotation and 1 $\mathrm{cm}$ for shortening [3]. Their frequency has decreased considerably in developed countries because of the preference for surgical treatment for an early recovery. But in developing countries, leg shaft mal-union are often due to traditional treatment or inadequate surgical materials to ensure appropriate management in hospital [1] [4]. The purpose of this work was to evaluate the anatomical and functional results of the surgical treatment of leg shaft mal-union in African environment.

\section{Material and Methods}

\subsection{Patients}

This was a retrospective study of patients operated for Leg shaft mal-union at Brazzaville University Hospital between January 2014 and December 2018. 1755 patients were admitted in our department, 23 patients presented with limb shaft mal-union (1.3\%). 9 of them presented with leg shaft mal-union. Of these 9 patients, 5 were selected for they met the inclusion criteria patients: Laming leg shaft mal-union. Shortening of more than $2 \mathrm{~cm}$ of the pelvic limb, an angulation of more than $10^{\circ}$ in the tibial segment, patients meeting 6 months or more a following the initial management. The studied parameters were epidemiological, including: frequency, age, sex, etiology, type of first management, type of mal-union, Clinical including: pain, type of deformation, quality of the walk, and therapeutic including: type of treatment offered and the results.

\subsection{Surgical Technique and Postoperative Care}

Surgery was performed in all patients with spinal anesthesia. The patients were placed supine on a regular table with a thigh support that allowed to bend the knee. The procedure was performed in the open and consisted of a double oblique osteotomy of the fibula and the tibia with lateral base for the correction of the varus, medial base for the correction of the valgus and with anterior base for the correction of the flessum. A " $Z$ " osteotomy was performed for the correction of the overlap. After relaxation of the tibial segment, the tibia was stabilized by a locked nail $(n=3)$ or a screwed plate $(n=2)$. Functional rehabilitation was systematic postoperatively. Standing was allowed at 1 month for patients managed with intramedullary nailing and at 4 months for patients managed with screwed plate.

\subsection{Evaluation Methods}

The anatomical evaluation was based on the quality of the leg's relaxation and bone healing, which is appreciated on the standard X-ray film. The functional 
evaluation was based on Thorensen's criteria [5].

\section{Results}

5 patients were selected for the study. They included 3 males and 2 females. Their age ranged from 27 to 59 years. ( 39 average)

Upon admission, all patients complained of leg deformity and pain, resulting in lameness significantly affecting the quality of the walk. The pain ranged between 5/10 and 7/10 according to the visual analogue scale. The fractures were due to a road accident $(n=4)$ and a fall $(n=1)$. They were closed in 3 patients and opened in 2 patients. The right side was involved 3 times and the left side 2 times. Initial treatment was orthopedic in 2 patients and traditional in 3 patients. Table 1 represents the distribution of patients according to the type of mal-union.

From an anatomical point of view, the reduction was anatomic in 3 patients operated by locked nail and non anatomical in 2 patients operated by screwed plate of which one underwent an early reoperation with replacement of the plate by an intramedullary nail with a distal locking screw (Figures $1(a)-(c)$ ). We then observed at 3 months of recovery, a secondary angulation on intramedullary nail.

9 months after surgical realignment, bone healing was achieved in all our patients. The average consolidation time was 4 months (range 3 to 7 months). We noted 1 case of residual mal-union in valgus of $5^{\circ}$ on screwed plate (Figure 2(a), Figure 2(b)) and 1 case of valgus angulation of $5^{\circ}$ on locked intramedullary nail.

Table 1. Distribution of patients according to the type of mal-union.

\begin{tabular}{ccc}
\hline Type of mal-union & Angulation & Number \\
\hline varus angulation & $15^{\circ}$ & 2 \\
valgus angulation & $15^{\circ}$ et $20^{\circ}$ & 1 \\
flexum angulation & $25^{\circ}$ & 5 \\
Total & & 2 \\
\hline
\end{tabular}

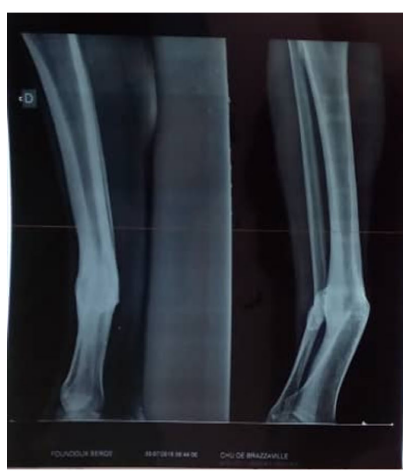

(a)

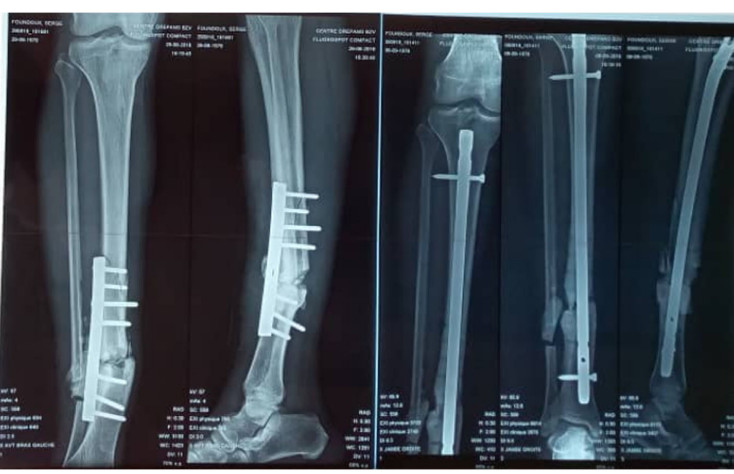

(b) (c)

Figure 1. (a) X-ray of the leg before the operation; (b) Non anatomical alignment managed by screwed plate; (c) Early reoperation with replacement of the screwed plate by an intramedullary nail. 


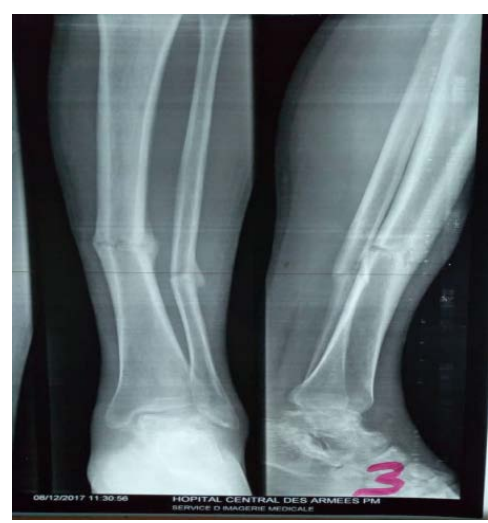

(a)

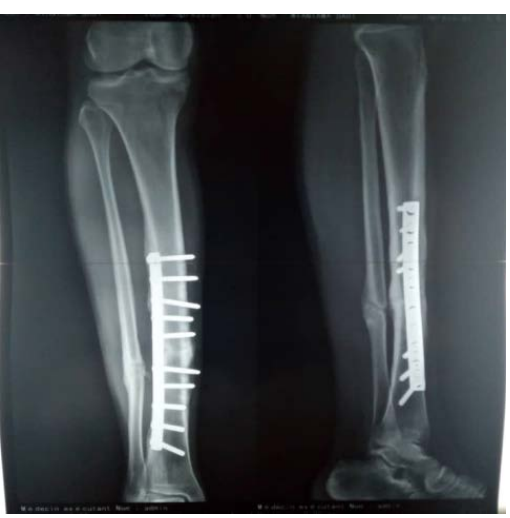

(b)

Figure 2. (a) X-ray of the leg before the operation; (b) X-ray showing bone consolidation managed by screwed plate with a $5^{\circ}$ valgus.

Functionally, walking was considered normal in 3 patients and in 2 patients, the wearing of a $2 \mathrm{~cm}$ heel was essential. According to Thorensen's criteria, the overall results at the average follow-up of 9 months were considered good in 3 patients and average in 2 patients.

\section{Discussion}

Shaft mal-union is a post-traumatic orthopedic pathology whose frequency is variable in the literature. In a series of osteosynthesis managed by screwed plate, the incidence of leg shaft mal-union varies from $1 \%$ to $22 \%$ in a study leg shaft mal-union managed by intramedullary nail the incidence varies from 0 to 37\% [6]. In our study the percentage was $1.3 \%$. Gogoua [1] and Boucher [7] Reported respectively $28.69 \%$ and of $77 \%$ of mal-unions in their series. The average age of our patients was 39, it is comparable to the results found in a study by Gogoua et al. [1]. The male predominance was also de case in our study, similar to the conclusion observed in various papers.

In our study, leg shaft mal-union were found to be caused by the recourse of traditional healers, poorly conducted orthopedic treatment in health institution lacking appropriate machinery and materials, and also the financial issues that prevented the patients from undergoing surgery.

Leg shaft mal-union due to traditional treatment are reported by many African authors [1] [4] [8].

Clinically, the symptoms were obvious. Patients consulted for leg deformity and debilitating lameness. The patient's history revealed a previous case fracture treated traditionally and orthopedically. These findings corroborates the data from the literature [1] [4]. The standard radiography was sufficient to make the diagnosis and assess the type leg shaft mal-union.

Mal-union with angulation the most encountered type in our study. The same results were observed in other authors [1] [2] [8].

Therapeutically, the operative technique used in our study was a tibial osteotomy open closure, associated with an osteotomy of the fibula. This attitude is 
standard according to the literature [1] [8] [9]. Other authors use the open osteotomy and bone graft technique [10].

Regarding the realignment of the leg, it was difficult and required minimal bone resection in a patient operated for varus mal-union and overlap. This is explained by muscle retraction due to the age of the fracture. The stability of the reduction was insured by a locked intramedullary nail or a screwed plate. In our study, alignment was more anatomical by nail than by screwed plate.

Intramedullary nailing is the treatment of choice for shaft fractures of long limb bones. Locking has extended its indications to complex shaft fractures and metaphyseal-diaphyseal fractures [11]. In our study, we observed a case of residual valgus on locked nail in a patient operated for distal leg mal-union. This can be explained by the lack of distal locking screws or premature standing. For Omar Margal et al. [11], the distal locking must have at least 2 screws to promote the stability of the assembly. Thoreux et al. [6] in his study reports that valgus leg shaft mal-union are often seen when the fracture sits at the distal quarter of the leg.

\section{Conclusion}

Leg shaft mal-union are common in developing countries. They cause serious functional consequences and considerably modify the quality of the walk. Osteotomy is the only therapeutic option to restore anatomy of the deformed limb and improve the quality of the walk.

\section{Informed Consent}

The publication of this clinical fact has been approved by the patient.

\section{Conflicts of Interest}

The authors declare that they have no competing interests.

\section{References}

[1] Gogoua, R.D., Anoumou, M., Koné, A. and Varango, G. (2007) Aspects épidémiologiques et thérapeutiques des cals vicieux des fractures diaphysaires des members au CHU de Treichville à Abidjan. Rev Int Sc. Med, 9, 55-60. http://revues-ufhb-ci.org/fichiers/FICHIR_ARTICLE_1661.pdf

[2] Feldman, D.S., Shin, S.S., Madan, S. and Koval, K.J. (2003) Correction of Tibial Malunion and Nonunion with Six-Axis Analysis Deformity Correction Using the Taylor Spatial Frane. Journal of Orthopaedic Trauma, 17, 549-554. https://doi.org/10.1097/00005131-200309000-00002

[3] Bhandari, M., Guyatt, G.H., Tong, D., Adili, A. and Shaughnessy, S.G. (2000) Reamed versus Non Reamed Intramedullary Nailing of Lower Extremity Long Bone Fractures: A Systematic Overview and Meta-Analysis. Journal of Orthopaedic Trauma, 14, 2-9. https://doi.org/10.1097/00005131-200001000-00002

[4] Moyikoua, A., Ngatsé-Oko, A., Bouity-Buang, Ondzoto, J.M., Kaya, J.M. and Pena-Pitra, B. (1992) Resultants du traitement initial des fractures ouvertes récentes des members. A propos de 150 cas traités au CHU de Brazzaville. Médecine 
d Afrique Noire, 39, 755-762.

[5] Thorensen, B.O., Alho, A., Ekeland, A., et al. (1985) Interlocking IM Nailing in Femoral Shaft Fractures. The Journal of Bone and Joint Surgery, 67A, 1313-1320. https://doi.org/10.2106/00004623-198567090-00002

[6] Thoreux, P. and Nordin, J.Y. (1995) Fractures fermées de la jambe de l'adulte. Encyclopédie Médico-Chirurgicale 14-086-A-10, 16.

[7] Boucher, M., Leone, J., Pierrynowski, M. and Bhandari, M. (2002) Three-Dimensional Assessment of Tibial Malunion after Intramedullary Nailing: A Preliminary Study. Journal of Orthopaedic Trauma, 16, 473-483. https://doi.org/10.1097/00005131-200208000-00005

[8] Tekpa, B.D., Dovi-Doumgba, A., Issa Mapouka, P.A., Nghario, L., Dégou, S.R. and Gaudeuille, A. (2017) Les cals vicieux diaphysaires du fémur de l'adulte traités par ostéotomie et ostéosynthèse à ciel ouvert à Bangui (République Centrafricaine). $J$ Afr Chir Orthop Traumatol, 2, 56-63.

http://indexmedicus.afro.who.int/aim/opac_css/doc_num.php?explnum_id=71371

[9] Santaro, D., Tantavisut, S., Aloj, D. and Karam, M.D. (2014) Diaphyseal Osteotomy after Post-Traumatic Malalignment. Current Reviews in Musculoskeletal Medicine, 7, 312-322. https://doi.org/10.1007/s12178-014-9244-9

[10] Kaba, A., Senlecq, C., Lao, A., Husseini, E.L.N., Pierchon, F. and Peyroux, L.M. (2015) Correction de cals vicieux et pseudarthroses supramalléolaires par fixateur externe d'Ilizarov évolution: Truelok R et Truelok Hexapodal, à propos de deux cas. Médecine et Chirurgie du Pied, 31, 38-43.

https://doi.org/10.1007/s10243-015-0402-6

[11] Margad, O., Boukhris, J., Sallahi, H., Azriouil, O., Daoudi, M. and Koulali, K. (2017) Intérêt de l'enclouage centromédullaire dans les fractures du quart distal de la jambe: À propos de 30 cas. Pan African Medical Journal, 28, 176-182.

https://doi.org/10.11604/pamj.2017.28.176.10261 